Orginal Article

\title{
Evaluation Of The Trochantertc Fracture Of The Femur Treated By Uniaxial External Fixator In Risk Elderly Patient.
}

\author{
AKM Zahiruddin1, S K Paul2, M L R Khan3, S N Alam4
}

\begin{abstract}
Trochanteric fractures occur in elderly osteoporotic patients with concomitant medical disorders, who are unable to tolerate lengthy periods of anaesthesia or any appreciable blood loss. For this reason, external fixation represents an attractive alternative. External fixation can be easily applied by modern equipments like c-arm. It is simple, quick, low cost with minimal surgical trauma, lower rate of morbidity, less operation time, shorter duration of hospital stay and early mobilization.This clinical study is the result of trochanteric fractures of the femur in high risk elderly patients treated with

\section{introduction}

Fractures of the trochanteric region of the femur occur more than the fracture of the neck of the femur in a ratio of about $3: 2$ Hip fracture accounts for $30 \%$ of bed occupied in the orthopedic institute1 The estimated cost for treatment is approximately 13.8 billion per year.2 There is no definite statistics in our country but from hospital record it is clear that every year it is increasing with the increase of the average life expectancy. The proximal part of femur have been marked as one of the biggest problem of the contemporary civilization. Trochanteric fracture is around 4 times more frequent than the proximal part of femur; women are 3 times more liable to the trochanteric.
\end{abstract}

1. AKM Zahiruddin Uddin

Assistant Professor

Ortho Surgery, NITOR, Dhaka.

2. Swapan Kumar Paul

Assistant Registrar

Ortho Surgery, NITOR, Dhaka.

3. Md. Lutfur Rahman Khan

Associate Professor

Ortho Surgery, NITOR, Dhaka.

4. Sk. Nurul Alam

Ex Director \& Professor of Ortho Surgery NITOR, Dhaka.

Corresponding author

AKM Zahiruddin Uddin

Ortho Surgery, NITOR, Dhaka. an external fixator on 11 patients over a period of 2 years from July 2005 to June 2007 at NITOR.The object of the study was to evaluate the outcome of operation. All the patients were in a poor general condition and with severe associated medical diseases and also more than one condition were present. The external fixator was removed after adequate clinical radiological sign of fracture union (averaged 16.54 weeks) as an out patient procedure. The overall radiological improvement was observed in 11 cases in 6 months followup. The overall satisfactory result was observed in 9 (81.8\%) and unsatisflictory

in

$2(18.2 \%)$.

ractures than men usually more than 65 years old, with greater loss of the skeletal mass1. Most of the fractures occur in the elderly, usually associated with osteoporosis and results from only moderate to minimum trauma.2 The treatment of trochanteric fracture has advanced in last few decades.3 Over the years, several surgical fixation techniques have been proposed. The most widely used implants are the sliding hip screw and intramedullary hip screw 4 while both of these techniques produces acceptable results, a number of problems associated with their use have been reported5, including penetration of the joint by the tip of the implant, Loss of reduction and rotationaldeformity lead to varus angulations, lag screw cutout, cortical screw pull out, implant bending and breakage.4-7 The sliding hip screw is currently most frequently used implant to fix a trochanteric fracture of the hip. Cut out of the lag screw is the commonest cause of fixation failure after sliding hip screw fixation. Fracture of this type frequently occur in elderly osteoporotic patients with concomitant medical disorders, who are unable to tolerate lengthy periods of anaesthesia or any appreciable blood loss. External fixation therefore, represents an attractive alternative.5 External fixation device was then abandoned because pintract infection, pin loosening. 8 Loosening of pins is due to improper technique of insertion. This can be reduced by improving the contact between the end of the fracture bone, increase the number of pins, stiffness of fixation and compression of the fracture site. 
The advantages of this technique are minimally invasive, lower rate of morbidity, less blood loss, less operation time, shorter duration of hospital stay, early mobilization and reduced rate of mechanical complication.9 Close reduction and external fixation of the trochanteric fracture are effective treatments can produce clinical outcomes equal to internal fixation, if not better than the outcomes obtained with conventional treatment. So external fixation technique is one of the good option for trochanteric fracture of the femur in high risk elderly ents.

\section{Patients and methods}

From July 2005 to June 2007 we treated 11 patients Comprising 9 female and 2 male, Average age was 78.63yrs. The causes of injury due to domestic fall comprised of 8 (72.7\%) patient and due to RTA 3 (27.3\%) patient. All the patients were in a poor general condition and with severe associated medical diseases and also more than one comorbidities were present in each of the case. Among them 3 patients were of kyle type-II. Seven patients were kyle type-III and 1 patient of kyle type-IV category. Mean period of follow up was 7 months. External fixator was removed after 16.54 weeks in average.

\section{Operative technique}

The methods were done in Operation Theater under spinal anaesthesia. Any associated illness such as hypertension, diabetes, pulmonary problem and concomitant injuries were treated. As soon as the general condition of the patients was settled, plan for operation was done. Patient was placed on a fracture table in the supine position with the uninjured limb widely abducted so that the fracture can be manipulated or controlled during surgery. Patient's buttocks were rested on the well-padded seat and padded counter traction post was placed between the thighs. Feet were attached to the foot piece of the fracture table. Reduction of fracture: Applying gentle traction to the affected limb in slight internal rotation and 15-20 degrees of abduction performed closed reduction of the fracture, until the fracture anatomically reduced. This reduction is confirmed by c-arm. This reduction is then maintained throughout the surgical procedure. In this study, uniaxial fixator was used. The principal implants are: Schanz screws: $5 \mathrm{~mm}$ in diameter for metaphysis $4.5 \mathrm{~mm}$ in diameter for diaphysis, Clamps, Stainless steel tubes. Insertion of the triple sleeve through stab incision and push on to the $2 \mathrm{~cm}$ below the flare of the greater trochanter midway between the anterior and posterior cortex along and parallel to the axis of the femoral neck at an angle of 110-130 degrees to the long axis of the diaphysis was done. Holding the sleeves steady and lightly tap the trocar onto the bone surface in order to create the initial impression. Removing of the trocher and insertion of the long $3.5 \mathrm{~mm}$ drill bit through the inner sleeve and drill should be directed toward the most proximal part of the femoral neck, parallel to the proximal cortex of the neck. A correct position should be carefully checked under c-arm. On the lateral view, a central position is ideal. The 1st proximal schanz screw $5 \mathrm{~mm}$ indiameter place onto the $\mathrm{T}$ handle and insert through outer sleeve into bone and advanced under carm. The tip of the screw was allowed to lie $1 \mathrm{~cm}$ from the articular surface until the threaded portion has passed across the fracture line. Correct alignment of this pin must be confirmed in two planes under c-arm. At this point a 2nd proximal schanz Screw $5 \mathrm{~mm}$ in diameter is inserted in the same manner as the first. So, that this path ideally should be parallel with respect to the 1st screw already inserted and close to the inferior cortex of the femoral neck and tip of the screw should lie $1 \mathrm{~cm}$ from the articular surface, the position confirmed under image intensification. In addition, three $4.5 \mathrm{~mm}$ distal Schanzs screw are inserted after predrilling. Ideally, these screws are introduced perpendicular to the longitudinal axis of the femur, but if the fracture line or the bone quality do not permit so, they could be inserted obliquely. However, these screws should always be inserted in the center of the diaphysis. Then introduce locking clamp set over the schanz screw. Then two 125 angle stainless steel tubes are introduced through locking clamp in parallel manner. The clamps are tightened and the final position checked radio logically. Traction is then discontinued, flexion extension of the hip and knee performed to make sure that there is no tethering of the skin around the bone screws. If any tautness of the skin is identified, it can be released by extending the incision around the screws. Dry dressing was applied around the screws. 


\section{Postoperative Followup}

All the patients after operation were kept under observation in the postoperative ward for next 24 hrs. Proper fluid and hemodynamic balance were taken care. Adequate analgesic and sedation were ensured by injection of pethedinc and diclofenac IM as needed. Posture was changed after every 2 hours. First postoperative day- The patient was allowed to sit on the bed the day after the surgery as directed by the comfort of the patient. Active exercise of the upper and lower limbs was begun. Breathing exercise was started. Plain AP and lateral radiographs were obtained on the first postoperative day and analyzed for reduction of the fracture and position of the schanz screw. Second postoperative day to onward- Depending on the general condition of the patients, type of fracture, nonweight bearing walking with walker was allowed on second post operative day. When pain permitted static quadriceps exercise, active abduction, flexion, extension of the hip were advised. Knee bending exercise was also taught. Ankle and toe movement were also encouraged. These exercise regimen were performed for 5-10 in mutes 10-12 times a day. Patients were discharged from hospital with crutch walking training. On discharge all the patients were advised physiotherapy for mobilization of knees and hip and to come again for follow-up.

\section{Results:}

During the period of July 2005 to June 2007 a total number of 14 patients were selected for this study. Out of these one patient died before discharge, one patient died within 3 weeks and also one patient was subsequently lost from follow up. Hence this study comprises 11 patients, all this 11 patients were followed up for 6 months to 12 months, age ranges from 65 to 95 years, mean age was 78.63 years, incidence of fracture was found more in female. Female was 9 (8 1.8\%) and male 2 (18.2\%).; Among the 11 patients, 7 (63.6\%) had right sided and 4 (36.4\%) left sided involvement.

Table-1: Distribution of type of fracture $(n-11)$

\begin{tabular}{|l|l|l|}
\hline \multicolumn{1}{|c|}{ Kyle type } & \multicolumn{1}{|c|}{ No. of Patients } & percentage \\
\hline Type-Il & 3 & 27.3 \\
\hline Type-Ill & 7 & 63.6 \\
\hline Type-IV & 1 & 9.1 \\
\hline Total & 11 & 100 \\
\hline
\end{tabular}

According to the Kyle's type, out of 11 patients, 3 (27.3\%) patients were of type-Il, 7 (63.6\%) patients were to type-III and 1 (9.i\%) patient was of type-IV category. All patients had associated illness and also more than one condition were present. Out of 11 patients 7 patients suffered from cardiovascular disease, 2 patients has severe anaemia, 2 patients had respiratory failure, 1 patients had cerebrovascular accident, 1 patient had diabetes mellitus. In the present study 1 (9.1\%) patient was operated within 1 week of injury, 9 (81.8\%) cases were operated between 1-2 weeks and 1 (9.1\%) patient was operated after 3 weeks. Duration of operation time-Out of 11 patients, 3 (27.3\%) patients were operated within 30-40 minutes, 7 (63.6\%) within 41-50 minutes and 1 (9.1\%) patient within 60 minutes. Duration of postoperative hospital stay was 2-4 days, 3 (27.3\%) patients stayed for 2 days, 4 (3 6.4\%) patients stayed for 3 days and also another 4 (36.4\%) patients stayed for 
4 days. In this series 2 (18.2\%) patients developed superficial pin tract infection, 1 (9.1\%) patients varus malunion, 1 (9.1\%) patients bedsore and 2 (18-2\%) patients had limb length discrepancy. In the present series, 2 (18.2\%) patients had taken for union 14-15 weeks, 7 (63..6\%) patients 16-17 weeks and 2 (18.2\%) patients 18-19 weeks. Mean union time was 16.54 weeks.

Table-2: Functional score and results (n-11)

Distribution of patients according to Harris Score (Harris, 1969

\begin{tabular}{|l|l|l|}
\hline Case SI. No. & Result & Functional score \\
\hline 1 & Excellent & 91 \\
\hline 2 & Good & 82 \\
\hline 3 & Good & 86 \\
\hline 4 & Excellent & 92 \\
\hline 5 & Good & 80 \\
\hline 6 & Good & 82 \\
\hline 7 & Good & 84 \\
\hline 8 & Good & 82 \\
\hline 9 & Good & 83 \\
\hline 10 & Fair & 72 \\
\hline $\mathrm{n}$ & Poor & 66 \\
\hline
\end{tabular}

In the present series excellent results were

achieved in 2 patients and good in 7 patients, fair in 1 patient and poor in 1 patient.

Table-3: Destitution of patients by functional outcome $(n=11)$

\begin{tabular}{|l|l|l|}
\hline Results & No. of patients & Percentage \\
\hline Excellent & 2 & 18.2 \\
\hline Good & 7 & 63.6 \\
\hline Fair & 1 & 9.1 \\
\hline Poor & 1 & 9.1 \\
\hline
\end{tabular}

In the present series, excellent results were achieved in 2 $(18.2 \%)$ and good in 7 (63.6\%), fair in $(9.1 \%)$ and poor in $(9.1 \%)$ Overall satisfactory results were $9(81.8 \%)$ and unsatisfactory 2 (18.2\%)

\section{Discussion}

There is no study in this institute on the outcome of trochanteric fractures of the femur in high risk elderly patients treated with an external fixator. Patients were above 65 years, mean age was 78.63 years)10-11 All the patients were treated by close reduction and stabilization by external fixator. Sex incidence was found 2 (18.2\%) were male, and 9 (81.8\%) were female11, this may be due to women are sufferer of post menopausal osteoporosis, negligence about diet and less active than male. Out of 11 patients, 3 (27.3\%) patients gave history of RTA, 8 (72.7\%) gave history of fall on the ground at home or outside home. Most (>85\%) of our population live in rural areas. Due to illiteracy, lack of supervision, low socioeconomic status, poor people attend in government hospital, Majority of the patients are treated late, ranging from several days to several weeks. The patients in developed countries are treated within 48-72 hours. In this series operations were performed after an average 
of 11.3 days. All the patientswere operated under spinal anaesthesia except 2 having local anaesthesia.11 In this seriesav erage operation time was 44.63 minutes 12 , It is worthy to mention here that no patient in this series developed thrombotic complication with low molecular weight heparin (enoxaparin) was given subcutaneously in a dose of $40 \mathrm{mg}$ once daily for 5 days2. One of the objectives of operative treatment is to reduce the post operative hospital stay and thereby reduce cost and burden on hospital and nursing staff. In the present series the mean postoperative hospital stay was 3.1 days. knee stiffness was a major problem in early cases. So the vastus lateralis was transfixed in the maximum stretched position. In this series postoperative complications were superficial pin tract infection 2, varus malunion 1, bedsore 1 , limb length discrepancy 2. But there was no loss of reduction and breakage of pins13. Out of 11 patients in this series, 1 patient had moderate pain due to varus angulations resulting in difficult close reduction. Most authors comment that superficial infection is common. In the present series there was no case of deep infection. Superficial pin tract infection in 2 (18.18\%)8, In this series external fixator were removed after an average of 17.27 weeks as an out patient procedure. Adequate clinical and radiological signs of fracture union average time 16.54 weeks.5 In the present series excellent results were achieved in 2and good in 7, fair in 1 and poor in 1 . Therefore satisfactory results were (excellent and good) 8 $1.8 \%$ and unsatisfactory (fair and poor) $18.2 \%$. This method of external fixation can be recommended in our population, study had several limitations. It was a small scale study. Physiotherapy was essential for the successful Outcome of the patients.

\section{Conclusion}

Trochanteric fracture frequently occurs in elderly osteoporosis patient with concomitant medical disorders, who are unable to tolerate lengthy period of anaesthesia or any appreciable blood loss. External fixation is therefore, an attractive. External fixation decreases the morbidity and mortality related to nonoperative treatment as it minimizes surgical damage and blood loss. ft allows early mobilization and reduces the length of hospital stay. So, rehabilitation is easier In these patients with better functional' outcome. It is also effective whenever early elective surgery is not possible. External fixation is the method of choice for high risk geriatric patients with trochanteric fracture. It is simple, economic, less operation time with low risk.

\section{References}

1. Larsson S, Friberg S, Hansson LI, 1990, Trochanteric fractures, Mobility, complications, and mortality in 607 cases treated with the sliding - screw technique. Clin Orthop Relat Res, Vol. 260,pp. 232-41.

2. Milenkovic S, Mitkovic M, Radenkovis N, Mlabenovic D, Golubovic Z, Stajolovic M, 2003, Surgical treatment of trochanteric Fractures of femur by using external and internal fixation devices, Medicine and Biology, vo 1.10(2), pp. 79-83.

3. Kyle R.F, 1994, Fracture of the proximal part of the femur, Journal ofBone and Joint Surgery (Br); vol. 76-A, pp. 924-948. Kyle RF, 1993 Fractures of 1/se lisp Gustilo RB, Kyle RF, Templeman DC jst edt vol 2, pp 783-854.

4. Moroni A, Faldinic, Pegreul Ii, Along-kim A, and Glannini S, 2005a Osteoporotic pertrochanteric fractures can be successfully treated with external fixation. J Bone Joint Surg Am, org volume, 87A:suplement-2, pp. 42-51.

5. Alcivar E, 2001, A new method of external fixation for proximal fractures of the femur. injury, 32 Suppl 4, pp. 107-44. 6. Bridle Patel A.D, Bricher M, Calvert P.T, 1991, Fixation of intertrochanteric Fracture of the femur: A randomized prospective comparison of the gama nail and DHS, Journal of Bone and Joint Surgery (Br), vol. 73-B, pp. 330-334.

7. Simon H, Pate! A, .Bircher M, Calvert P, 1991, Fixation of trochanteric Fracture femur, Journal of Bone and Joint Surgery, vol. 73-B, pp. 330- 334.

8. Vossinakis 1.C, Badras L.S; 2002. The external fixator compared with the sliding hip screw for pertrochanteric fractures of the femur. J Bone Joint SurgAm vol. 84-B, pp. 2329.

9.Baumgaerttner MR. 2002, The pertrochanteric external fixator reduced pain, hospital stay, and mechanical complications in comparison with the sliding hip screw. JBone Joint Surg Am, 84, p. 1488.

10. Kourtzis N, Pafilas D, Kasimatis G, 2001, Management of pertrochanteric fractures in the elderly patients with an external fixation. Injury. mt. J. 32 SupI 4, pp. 1 5-28.

11. Gotfried Y, Frish E, David G, Mendes, Roffman M, 1985, Intertrochanteric fractures in high risk geriatric patients treated by external fixation, Orthopaedics, vol. 8, no. 6, pp. 769-774.

12. Devgon A, Sangwan SS, 2002, External fixator in the management of trochanteric fractures in high risk geriatric patients- a friend to the elderly. ladiaa Jaaraal Med Scicace, vol. 56, issue. 8, pp. 385-390.

13. Kamble K.T, Murthy BS, Pat V and Rao KS, 1996, External fixation in unstable Intertrochanteric fractures of femur, Injury, vol. 27, no. 2, pp. 139-142. 